\title{
Spotlight on ibrutinib and its potential in frontline treatment of chronic lymphocytic leukemia
}

\author{
This article was published in the following Dove Press journal: \\ OncoTargets and Therapy \\ 29 March 2017 \\ Number of times this article has been viewed
}

\author{
Maliha Khan \\ Jamie L Gibbons \\ Alessandra Ferrajoli \\ Department of Leukemia, The \\ University of Texas MD Anderson \\ Cancer Center, Houston, TX, USA
}

Correspondence: Alessandra Ferrajoli Department of Leukemia, The University of Texas MD Anderson Cancer Center, I5I 5 Holcombe Blvd. Unit 428, Houston, TX 77030, USA

Email aferrajo@mdanderson.org

\begin{abstract}
Chronic lymphocytic leukemia (CLL) is the most prevalent leukemia in the adult population. Current efforts are focused on better understanding the intricate pathophysiology of the disease to develop successful targeted therapies. Ibrutinib is emerging as an important agent in this new age of targeted treatment for CLL. As a Bruton's tyrosine kinase inhibitor, it blocks the signaling pathway that malignant B-lymphocytes need for growth and maturation. Ibrutinib's role in therapy was further expanded recently when the US Food and Drug Administration approved its use in both frontline and salvage treatment for patients with CLL. This review assesses the effectiveness of ibrutinib in the frontline setting, its efficacy in various types of patients with CLL, and its safety and tolerability.
\end{abstract}

Keywords: ibrutinib, CLL, frontline therapy

\section{Background}

Chronic lymphocytic leukemia (CLL) is the most common leukemia in the Western adult population. ${ }^{1}$ In $2015, \sim 14,620$ new CLL cases were reported in the USA. CLL is more prevalent among whites, in particular males, and the median age at diagnosis is 72 years. $^{2}$ The hallmark of this disease is the accumulation of clonal B lymphocytes in the bone marrow, peripheral blood, and lymphoid tissues. These lymphocytes have a characteristic immunophenotype with co-expression of CD5, CD19, and CD23; expression of CD20 dim, CD79b, and surface immunoglobulins (sIg); and Ig light chain restriction. ${ }^{3}$ Constitutive activation of B-cell receptor (BCR) signaling is also a hallmark of CLL. This signaling pathway is critical for B-cell survival ${ }^{4,5}$ and has a central role in proliferation, apoptosis, differentiation, and cell migration during normal B-cell development. Stimulation of the BCR depends on phosphorylation of Bruton's tyrosine kinase (BTK), a kinase located downstream of the BCR. The development of novel inhibitors that target these specific kinases responsible for BCR signal transduction, such as BTK, has revolutionized the treatment of CLL. Consequently, treatment guidelines for this disease have also been updated.

\section{Indication for therapy in CLL}

CLL is a remarkably heterogeneous disease with a variable clinical course. Although a small proportion of patients may never require clinical intervention, most patients eventually need treatment at some point in their disease course. The pattern of disease progression also varies among patients. Thus, there are multiple indications for initial treatment of CLL, including rapidly proliferating lymphocytosis, bulky lymphadenopathy, disease-associated cytopenias, and worsening constitutional symptoms. Specific indications for treatment based on the 2008 International Workshop 
on Chronic Lymphocytic Leukemia (IWCLL)-sponsored Working Group recommendations are summarized in Table $1 .{ }^{6}$ Multiple factors, including patient age, performance status, comorbidities, molecular markers, and cytogenetic characteristics, must be considered before selecting the optimal treatment regimen and initiating therapy for patients with CLL.

\section{Risk stratification in patients requiring frontline therapy}

Once a CLL patient presents with an indication for frontline treatment, it is essential to evaluate the patient's disease characteristics and overall performance status before deciding on the appropriate therapy. One of the primary considerations is patient's age. Typically, a patient $>65$ years would not be considered as a candidate for frontline chemoimmunotherapy, either with fludarabine, cyclophosphamide, and rituximab (FCR) or with combined bendamustine and rituximab (BR). These regimens have higher toxicities in this population, most notably myelosuppression, and associated infective complications. ${ }^{7}$ In addition, older patients do not respond as well to chemoimmunotherapy, as demonstrated by the lack of improvement in their progression-free survival (PFS) and overall survival (OS) statistics. ${ }^{8}$ The standard-of-care treatment in this patient population is chlorambucil combined with a CD20-targeting monoclonal antibody such as rituximab, obinutuzumab, or ofatumumab. The median PFS in patients receiving chlorambucil and CD20-targeting monoclonal antibodies combination therapy was between 16 and 29 months, whereas in patients receiving chlorambucil monotherapy, the median PFS was between 11 and 13.1 months. ${ }^{9}$ The German CLL Study Group reported median PFS of 26.7 months with obinutuzumab-chlorambucil combination, and 16.3 months with rituximab-chlorambucil, compared with PFS of 11.1 months with chlorambucil alone. ${ }^{10}$ For physically fit

Table I Indications for treatment initiation according to the International Workshop on Chronic Lymphocytic Leukemia (IWCLL) ${ }^{6}$

I Advanced clinical stage of the disease (Rai stage III or IV, Binet stage C)

2 A significant or progressive lymphadenopathy (longest dimension $>10 \mathrm{~cm}$ ) or splenomegaly ( $>6 \mathrm{~cm}$ below the costal margin)

3 Cytopenia due to disease progression or autoimmune disorders (lack of response to corticosteroids or other standard treatments)

4 General symptoms (weight loss, fever, fatigue, infection)

5 Lymphocyte doubling time of $<6$ months or an increase of $>50 \%$ in $<2$ months (in patients with lymphocytosis $<30 \mathrm{~g} / \mathrm{L}$, this doubling time should not be the only indication for treatment) patients who are $<65$ years, chemoimmunotherapy is still an option, given the possibility of long-lasting remissions in patients with favorable prognostic factors.

Any underlying medical conditions, if present, also influence the choice of treatment. Patients with renal insufficiency have a higher risk of toxicity with many chemotherapy agents including fludarabine and bendamustine, due to delayed excretion and metabolism of the drugs. ${ }^{11}$ It is thus prudent to consider agents that have milder adverse effects or that have less impact on renal function. For patients with a history of hepatitis, special consideration must be made before initiation of treatment with CD20 monoclonal antibodies, since their use has been associated with reactivation of viral hepatitis. ${ }^{12}$ Patients with chronic comorbidities including chronic obstructive pulmonary disease, diabetes, and congestive heart failure are at higher risk of infective complications while receiving therapy; thus, therapy choices for these patients should include agents with fewer myelosuppressive effects and carefully selected antimicrobial prophylaxis. ${ }^{13}$

The somatic hypermutation status of the immunoglobulin heavy chain variable ( $I G H V$ ) gene is yet another factor to consider when making treatment decisions. As part of the natural maturation of B cells, mutations are introduced into the $I G H V$ genes, equipping the B cells with the ability to confront foreign elements as part of the immune response. ${ }^{14}$ Patients whose CLL cells have $<2 \%$ deviation from the germ line and thus have fewer introduced mutations are classified as having unmutated $I G H V$, whereas those with $>2 \%$ deviation are classified as having mutated $I G H V$. Patients with unmutated $I G H V$ have a poorer prognosis and have fewer lasting responses to chemoimmunotherapy combinations. ${ }^{15}$

Genomic abnormalities that are identified by fluorescence in situ hybridization studies before the start of therapy are very important, particularly in patients with del17p. Various studies have reported that patients with TP53 deletions (deletion 17p13.1) have more aggressive disease characteristics due to the role of these genes in maintaining genomic stability. ${ }^{16}$ The TP53 gene is a key part of tumor suppression since it codes for a protein that regulates cell division and prevents cells from undergoing uncontrolled duplication. ${ }^{17}$ Because part of the mechanism of action of chemotherapeutic agents is initiating apoptosis by stimulating the DNA damage response pathway, patients with deletions in the TP53 gene do not respond as effectively to therapy. ${ }^{18}$ Overall, a TP53 deletion, due to its direct involvement in tumor suppression, is commonly viewed as the worst prognostic marker in CLL and is associated with the most rapidly advancing disease. ${ }^{19,20}$ 


\section{Ibrutinib}

Ibrutinib is classified as a BTK inhibitor. BTK is a member of the TEC kinase family and has been implicated in the pathogenesis of several B-cell disorders, including CLL. BTK is a signaling molecule in the B-cell antigen receptor and in cytokine receptor pathways. Without functional BTK molecules, malignant tumor B cells fail to receive appropriate growth and maturation signals. ${ }^{21}$ Blocking BTK-initiated pathways thereby renders CLL cells unable to proliferate. Specifically, ibrutinib works by selectively and irreversibly binding the Cys-481 residue in the allosteric inhibitory domain TK/SH1 of BTK. Selective binding of the Cys-481 residue inhibits autophosphorylation of BTK at Tyr-223, preventing the activation of BTK. ${ }^{22,23}$

\section{Pharmacology}

Ibrutinib is orally administered and rapidly absorbed, with a peak plasma concentration at $2 \mathrm{~h}$ after dosing. A phase 1 , open-label, dose-escalation trial demonstrated that administration of ibrutinib in fasting patients, compared with its coadministration with food, reduced absorption by $\sim 60 \%{ }^{24}$

Ibrutinib is metabolized primarily in the liver through CYP3A. Co-administration of ibrutinib with CYP3A inhibitors is not recommended because strong CYP3A inhibitors can increase the concentration of ibrutinib 24- to 29-fold. ${ }^{25}$ The metabolites of ibrutinib are primarily eliminated in feces, with $<10 \%$ being eliminated by the kidneys. ${ }^{23}$ For this reason, ibrutinib remains a feasible option for CLL patients with renal insufficiency.

\section{Administration}

The current recommended dose of ibrutinib in CLL patients is $420 \mathrm{mg}$ (three $140-\mathrm{mg}$ capsules) orally once a day. ${ }^{22}$

\section{Toxicities}

The most common adverse effects of ibrutinib are neutropenia, anemia, thrombocytopenia, diarrhea, musculoskeletal pain, nausea, rash, bruising, fatigue, pyrexia, upper respiratory infection, dizziness, and hemorrhage, occurring in $>20 \%$ of patients. ${ }^{26-30}$ Other less frequent adverse reactions include atrial fibrillation (in 6\%-9\% of patients) and hypertension (in $6 \%-17 \%$ of patients). ${ }^{25}$ The adverse effect most commonly encountered in clinical trials with ibrutinib is diarrhea; however, diarrhea associated with the use of ibrutinib usually does not require treatment and resolves without discontinuation of this agent. Although myelosuppression (grade 1 or 2 ) has also been reported with ibrutinib, it is usually not as severe as that associated with chemotherapy regimens and only occasionally warrants treatment discontinuation. ${ }^{31}$ Despite irreversible inhibition of BTK, the risk of immunosuppression appears to decline with continued use of ibrutinib. A clinical study that examined this trend found that the average rate of infection declined from 7.1 per 100 patient-months during the first 6 months to 2.6 per 100 patient-months with an accompanying increase in IgA levels. ${ }^{32}$

Ibrutinib has been associated with an increased incidence $(3.5 \%-6.5 \%)$ of atrial fibrillation. The cause of this effect has been hypothesized to be the inhibition of cardiac PI3K-Akt associated with BTK-related kinases present in the atrial wall. ${ }^{33}$ In a number of trials, an increased risk of bleeding events, even with normal platelet counts, was shown to be another hematological adverse effect associated with ibrutinib use. ${ }^{26,32,34}$ Because the prothrombin time was unaffected in these patients, researchers attributed the bleeding events to platelet dysfunction, such as a collagen- and ADP-dependent platelet response secondary to CLL and/or ibrutinib. It was later discovered that BTK is a non-redundant mediator of platelet glycoprotein VI signaling, which was inhibited by ibrutinib; cessation of the drug reversed this inhibition. ${ }^{35}$ Given these effects, it is recommended that the use of ibrutinib be discontinued 3-7 days before any planned surgical procedures. Concomitant therapy with warfarin is also contraindicated; low-molecular-weight heparin is preferred..$^{24,26}$

\section{Ibrutinib in the frontline setting}

\section{Ibrutinib as a single agent}

The proven efficacy of ibrutinib in patients with relapsed and refractory CLL prompted investigators to conduct clinical trials with ibrutinib as a first-line agent. In an open-label, phase 1b/2 trial, 31 patients aged 65 years or older with CLL or small lymphocytic lymphoma received first-line treatment with ibrutinib. ${ }^{36}$ Of these patients, $71 \%$ demonstrated an objective response, defined as either a complete or partial response. In addition to responses based on standard criteria, the study reported that $13 \%$ of patients showed a partial response with lymphocytosis. Importantly, at follow-up (at a median of 22.1 months), disease progression had occured in only one patient receiving ibrutinib who developed Richter's transformation. This study also showed a favorable toxicity profile for ibrutinib. The majority of noted adverse events were grade 2 or lower, and there were no deaths due to treatment-related adverse events. In addition, only two patients discontinued ibrutinib due to toxicities, one for grade 3 fatigue and another for grade 2 viral infection. ${ }^{36}$

The RESONATE study, a multicenter, randomized, phase 3 clinical trial, found that PFS in patients with TP53 deletions 
who were treated with ibrutinib was significantly superior to that in patients treated with ofatumumab. ${ }^{37}$ At 6 months, the rate of PFS was $88 \%$ for patients receiving ibrutinib and $65 \%$ for those receiving ofatumumab. At 12 months, the OS rates were $90 \%$ in the ibrutinib group and $81 \%$ in the ofatumumab group, with overall response rates of $42.6 \%$ and $4.1 \%$, respectively.

A more recent study performed at the National Institutes of Health Clinical Center further supported the efficacy of ibrutinib in patients with a TP53 aberration. In this study, 33 patients with untreated CLL and 16 patients with relapsed or refractory disease were treated with ibrutinib. In the untreated CLL group, $97 \%$ of patients achieved an objective response at 24 weeks, with only one patient experiencing disease progression before this end point. Of the previously treated patients, $80 \%$ achieved an objective response and $20 \%$ had stable disease at 24 weeks. At 2 years, the cumulative incidence of progression was only $9 \%$ in the untreated patients and $20 \%$ in the previously treated patients, both of which were impressive figures compared with the cumulative incidence of progression observed in previous studies, which was much higher in these patient populations. ${ }^{38}$

In a single-arm trial that enrolled 132 patients with CLL, 31 had newly diagnosed disease for which they had received no previous treatment. To investigate the efficacy of ibrutinib as a frontline therapeutic agent, the data from these 31 patients were analyzed separately. The overall response rate in these patients was $84 \%$, with a complete response in $23 \%$. PFS and OS at 20 months were achieved by $96 \%$ and $97 \%$ of the patients, respectively. A subsequent report with a longer follow-up showed that responses to treatment with ibrutinib are sustained, with $96 \%$ of patients being free of progression at a median follow-up of 30 months. ${ }^{39}$

One of the most relevant studies illustrating the efficacy of ibrutinib in treatment-naïve patients is the RESONATE-2 trial, an international, open-label, randomized phase 3 trial comparing ibrutinib and chlorambucil in untreated older patients with CLL or small lymphocytic lymphoma. ${ }^{31}$ At a median follow-up of 18 months, PFS was $90 \%$ in the ibrutinib group compared with $52 \%$ in the chlorambucil group. Furthermore, the risk of progression or death was $84 \%$ lower with ibrutinib than with chlorambucil. What is remarkable in the initial results of this trial was that the favorable outcomes of ibrutinib therapy extended to high-risk populations, including patients with Rai stage III or IV disease, those with chromosome 11q22.3 deletion, and those with unmutated $I G H V$, all subgroups that have tended to have inferior responses to previous standard-of-care therapies. For example, PFS at 18 months was equal in the unmutated $I G H V$ and mutated $I G H V$ subgroups at $89 \%$. In addition to efficacy, the RESONATE-2 trial supported the overall safety and tolerability of ibrutinib. The frequency of adverse events, specifically fatigue, nausea, vomiting, and myelosuppression, was higher in the chlorambucil group. Moreover, only $9 \%$ of patients in the ibrutinib group required discontinuation of therapy due to adverse events, compared with $23 \%$ of patients receiving chlorambucil. $^{31}$

\section{Ibrutinib in combination}

Additional trials are trying to identify agents that can be used in combination with ibrutinib in a frontline setting. The combination of ibrutinib and rituximab in a phase 2 study showed a reduction in the duration of redistribution lymphocytosis in high-risk CLL patients along with a higher rate of clinical responses, with an objective response rate of $93 \% .{ }^{29}$ Another example is an ongoing phase $1 \mathrm{~b} / 2$ study of ibrutinib combined with obinutuzumab in untreated patients. ${ }^{40}$ The primary objectives of this study are to gauge the safety, tolerability, dose-limiting toxicity, and overall response rate of this combination. In addition to the combination of ibrutinib with monoclonal antibodies, other clinical studies are assessing the role of ibrutinib combined with chemotherapy. In a randomized, placebo-controlled, phase 3 HELIOS trial, the addition of ibrutinib to bendamustine and rituximab improved clinical outcomes without compromising safety. Furthermore, it reduced the risk of progression and death by $80 \% .{ }^{41}$ Ongoing trials are seeking to establish additional combination drug regimens with ibrutinib that may prove beneficial. For example, an ongoing phase 2 study at The University of Texas MD Anderson Cancer Center is investigating the efficacy of first-line therapy with ibrutinib, fludarabine, cyclophosphamide, and obinutuzumab in patients with mutated $I G H V .^{42}$ The growing number of such trials suggests ibrutinib's potential in the future of CLL treatment. Table 2 lists the studies using ibrutinib as frontline treatment for CLL.

\section{Future prospects}

Ibrutinib is emerging as an effective and safe targeted oral agent for the treatment of CLL. In the era of increasing concern for developing resistance to chemotherapeutic agents, ibrutinib provides an alternative to cytotoxic drugs and has become a viable choice of treatment in both frontline and relapsed settings. However, additional research is critical to improving our understanding of ibrutinib's long-term efficacy, toxicity, and methods of resistance. Further work is 
Table 2 Studies with ibrutinib as frontline treatment for chronic lymphocytic leukemia

\begin{tabular}{|c|c|c|c|c|c|c|c|}
\hline Study & $\begin{array}{l}\text { No of } \\
\text { patients }\end{array}$ & $\mathbf{R} / \mathbf{R}$ & Treatment & $\begin{array}{l}\text { Median age, } \\
\text { range (years) }\end{array}$ & ORR\% & PFS (months) & OS (months) \\
\hline Burger et $\mathrm{al}^{29}$ & 40 & $\begin{array}{l}\text { Yes: } 36 \\
\text { No: } 4^{a}\end{array}$ & Ibrutinib + rituximab & $63(35-82)$ & 95 & 18 (78\%) & I 8 (83.8\%) \\
\hline O'Brien et $\mathrm{al}^{36}$ & 31 & No & $\begin{array}{l}\text { Ibrutinib (low dose } \\
\text { vs high dose) }\end{array}$ & 71 (65-84) & 71 & $24(96 \%)$ & $24(96 \%)$ \\
\hline Byrd et $\mathrm{al}^{39}$ & $31^{\mathrm{b}}$ & No & Ibrutinib & 71 (65-84) & 84 & $20(96 \%)$ & 20 (97\%) \\
\hline Farooquij ${ }^{38}$ & $33^{b}$ & No & $\begin{array}{l}\text { Ibrutinib (untreated } \\
\text { vs treated) }\end{array}$ & $62(33-82)$ vs $62(56-79)$ & 97 & 24 (91\% vs $80 \%)$ & 24 (84\% vs $74 \%)$ \\
\hline Burger et $\mathrm{al}^{31}$ & 269 & No & $\begin{array}{l}\text { Ibrutinib } \\
\text { vs chlorambucil }\end{array}$ & $73(65-89)$ vs $72(65-90)$ & 86 vs 35 & I 8 ( $90 \%$ vs $52 \%), P<0.00$ I & 24 ( $98 \%$ vs $85 \%), P=0.00 \mathrm{I}$ \\
\hline
\end{tabular}

Notes: a Four patients with untreated disease. ${ }^{b}$ Data only of those patients receiving initial therapy with ibrutinib are shown.

Abbreviations: ORR, overall response rate; OS, overall survival; PFS, progression-free survival; R/R, relapsed/refractory.

needed to understand the characteristics and aggressiveness of the CLL clones that emerge in patients who are resistant to ibrutinib and to determine optimal second-line therapy for these patients. One mechanism of resistance to ibrutinib is the development of a BTK (C-481S) mutation that is associated with reduced affinity for ibrutinib and reduced inhibition of this agent. ${ }^{43}$ Understanding the mechanisms associated with the development of resistance to ibrutinib will be an important step in moving forward.

An additional area of focus in this age of targeted oral therapy for CLL is determining the best timing for administering these drugs in the frontline setting. The German Cooperative Study Group is currently addressing this question in its CLL12 trial, a placebo-controlled, double-blind, phase 3 study investigating whether early intervention with ibrutinib in intermediate- or high-risk patients improves event-free survival. ${ }^{21}$ Results from this ongoing trial and from similar studies, together with long-term follow-up in large randomized studies, will further define the future role of ibrutinib in the initial treatment of patients with CLL.

\section{Disclosure}

The authors report no conflict of interest in this work.

\section{References}

1. Elter T, Hallek M, Engert A. Fludarabine in chronic lymphocytic leukaemia. Expert Opin Pharmacother. 2006;7(12):1641-1651.

2. Siegel RL, Miller KD, Jemal A. Cancer statistics, 2015. CA Cancer J Clin. 2015;65(1):5-29.

3. Mir MA. Chronic lymphocytic leukemia: practice essentials, pathophysiology, etiology. Emedicinemedscapecom. 2016. [Updated September 7, 2016]. Available from: http://emedicine.medscape.com/article/199313overview. Accessed August 12, 2016

4. Rokosz LL, Beasley JR, Carroll CD, et al. Kinase inhibitors as drugs for chronic inflammatory and immunological diseases: progress and challenges. Expert Opin Ther Targets. 2008;12(7):883-903.

5. Kurosaki T, Hikida M. Tyrosine kinases and their substrates in B lymphocytes. Immunol Rev. 2009;228(1):132-148.
6. Hallek M, Cheson BD, Catovsky D, et al. Guidelines for the diagnosis and treatment of chronic lymphocytic leukemia: a report from the International Workshop on Chronic Lymphocytic Leukemia updating the National Cancer Institute-Working Group 1996 guidelines. Blood. 2008;111(12):5446-5456.

7. Eichhorst BF, Busch R, Stilgenbauer S, et al. First-line therapy with fludarabine compared with chlorambucil does not result in a major benefit for elderly patients with advanced chronic lymphocytic leukemia. Blood. 2009;114(16):3382-3391.

8. Woyach JA, Ruppert AS, Rai K, et al. Impact of age on outcomes after initial therapy with chemotherapy and different chemoimmunotherapy regimens in patients with chronic lymphocytic leukemia: results of sequential Cancer and Leukemia Group B studies. J Clin Oncol. 2013;31(4):440-447.

9. Hillmen P, Robak T, Janssens A, et al. Chlorambucil plus ofatumumab versus chlorambucil alone in previously untreated patients with chronic lymphocytic leukaemia (COMPLEMENT 1): a randomised, multicentre, open-label phase 3 trial. Lancet. 2015;385(9980): $1873-1883$

10. Goede V, Fischer K, Busch R, et al. Obinutuzumab plus Chlorambucil in patients with CLL and coexisting conditions. $N$ Engl J Med. 2014;370(12):1101-1110.

11. Nordstrom BL, Knopf KB, Teltsch DY, Engle R, Beygi H, Sterchele JA. The safety of bendamustine in patients with chronic lymphocytic leukemia or non-Hodgkin lymphoma and concomitant renal impairment: a retrospective electronic medical record database analysis. Leuk Lymphoma. 2014;55(6):1266-1273.

12. Salvana EM, Salata RA. Infectious complications associated with monoclonal antibodies and related small molecules. Clin Microbiol Rev. 2009;22(2):274-290.

13. Chao C, Page JH, Yang SJ, Rodriguez R, Huynh J, Chia VM. History of chronic comorbidity and risk of chemotherapy-induced febrile neutropenia in cancer patients not receiving G-CSF prophylaxis. Ann Oncol. 2014;25(9):1821-1829.

14. Dunn-Walters D, Thiede C, Alpen B, Spencer J. Somatic hypermutation and B-cell lymphoma. Philos Trans R Soc Lond B Biol Sci. 2001;356(1405):73-82.

15. Hamblin TJ, Davis Z, Gardiner A, Oscier DG, Stevenson FK. Unmutated Ig VH genes are associated with a more aggressive form of chronic lymphocytic leukemia. Blood. 1999;94(6):1848-1854.

16. Greipp PT, Smoley SA, Viswanatha DS, et al. Patients with chronic lymphocytic leukaemia and clonal deletion of both $17 \mathrm{p} 13.1$ and 11q22.3 have a very poor prognosis. Br J Haematol. 2013;163(3): 326-333.

17. Rivlin N, Brosh R, Oren M, Rotter V. Mutations in the p53 tumor suppressor gene. Genes Cancer. 2011;2(4):466-474.

18. Abrisqueta $\mathrm{P}$, Crespo M, Bosch F. Personalizing treatment for chronic lymphocytic leukemia. Expert Rev Hematol. 2011;4(1):27-35. 
19. Strati P, Keating MJ, O’Brien SM, et al. Outcomes of first-line treatment for chronic lymphocytic leukemia with $17 \mathrm{p}$ deletion. Haematologica. 2014;99(8):1350-1355.

20. Schnaiter A, Stilgenbauer S. 17p deletion in chronic lymphocytic leukemia: risk stratification and therapeutic approach. Hematol Oncol Clin North Am. 2013;27(2):289-301.

21. Langerbeins $\mathrm{P}$, Bahlo J, Rhein C, et al. The CLL12 trial protocol: a placebo-controlled double-blind Phase III study of ibrutinib in the treatment of early-stage chronic lymphocytic leukemia patients with risk of early disease progression. Future Oncol. 2015;11(13): 1895-1903.

22. MedlinePlus. Ibrutinib. National Institutes of Health, U.S. National Library of Medicine. [updated September 15, 2015] Available from: https://medlineplus.gov/druginfo/meds/a614007.html. Accessed August 12, 2016.

23. Pan Z, Scheerens H, Li SJ, et al. Discovery of selective irreversible inhibitors for Bruton's tyrosine kinase. ChemMedChem. 2007;2(1): 58-61.

24. de Jong J, Sukbuntherng J, Skee D, et al. The effect of food on the pharmacokinetics of oral ibrutinib in healthy participants and patients with chronic lymphocytic leukemia. Cancer Chemother Pharmacol. 2015;75(5):907-916.

25. Pharmacyclics. Imbruvica ${ }^{\circledR}$ (ibrutinib). Sunnyvale, CA: Pharmacyclics; 2016. Available from: https:/www.imbruvica.com/docs/ librariesprovider7/default-document-library/prescribing_information. pdf. Accessed August 12, 2016.

26. Zou Y, Xiao J, Tu Z, et al. Structure-based discovery of novel 4,5,6trisubstituted pyrimidines as potent covalent Bruton's tyrosine kinase inhibitors. Bioorg Med Chem Lett. 2016;26(13):3052-3059.

27. Brown JR, Hillmen P, O'Brien S, et al. Updated efficacy including genetic and clinical subgroup analysis and overall safety in the phase 3 RESONATETM trial of ibrutinib versus ofatumumab in previously treated chronic lymphocytic leukemia/small lymphocytic lymphoma. Blood. 2014;124(21):3331.

28. U.S. Food and Drug Administration. FDA expands approved use of Imbruvica for chronic lymphocytic leukemia. U.S. Department of Health and Human Services. [Updated July 28, 2014] Available from: http://www.fda.gov/NewsEvents/Newsroom/PressAnnouncements/ ucm406916.htm. Accessed August 12, 2016.

29. Burger JA, Keating MJ, Wierda WG, et al. Safety and activity of ibrutinib plus rituximab for patients with high-risk chronic lymphocytic leukaemia: a single-arm, phase 2 study. Lancet Oncol. 2014;15(10):1090-1099.

30. Jaglowski SM, Jones JA, Flynn JM, et al. A phase Ib/II study evaluating activity and tolerability of BTK inhibitor PCI-32765 and ofatumumab in patients with chronic lymphocytic leukemia/small lymphocytic lymphoma (CLL/SLL) and related diseases. J Clin Oncol. 2012; 30(suppl 15):6508.
31. Burger JA, Tedeschi A, Barr PM, et al. Ibrutinib as initial therapy for patients with chronic lymphocytic leukemia. $N$ Engl J Med. 2015; 373(25):2425-2437.

32. Byrd JC, Furman RR, Coutre SE, et al. Targeting BTK with ibrutinib in relapsed chronic lymphocytic leukemia. $N$ Engl J Med. 2013; 369(1):32-42.

33. McMullen JR, Boey EJ, Ooi JY, Seymour JF, Keating MJ, Tam CS. Ibrutinib increases the risk of atrial fibrillation, potentially through inhibition of cardiac PI3K-Akt signaling. Blood. 2014;124(25):3829-3830.

34. Byrd JC, Hillmen P, James DF. Response: additional data needed for a better understanding of the potential relationship between atrial fibrillation and ibrutinib. Blood. 2015;125(10):1673.

35. Lipsky AH, Farooqui MZ, Tian X, et al. Incidence and risk factors of bleeding-related adverse events in patients with chronic lymphocytic leukemia treated with ibrutinib. Haematologica. 2015;100(12): 1571-1578.

36. O'Brien S, Furman RR, Coutre SE, et al. Ibrutinib as initial therapy for elderly patients with chronic lymphocytic leukaemia or small lymphocytic lymphoma: an open-label, multicentre, phase 1b/2 trial. Lancet Oncol. 2014;15(1):48-58.

37. Byrd JC, Brown JR, Barrientos JC, et al. Ibrutinib versus ofatumumab in previously treated chronic lymphoid leukemia. NEnglJMed. 2014;371(3): 213-23.

38. Farooqui MZ, Valdez J, Martyr S, et al. Ibrutinib for previously untreated and relapsed or refractory chronic lymphocytic leukaemia with TP53 aberrations: a phase 2, single-arm trial. Lancet Oncol. 2015;16(2): 169-176.

39. Byrd JC, Furman RR, Coutre SE, et al. Three-year follow-up of treatment-naïve and previously treated patients with CLL and SLL receiving single-agent ibrutinib. Blood. 2015;125(16):2497-2506.

40. ClinicalTrials.gov. Ibrutinib in combination with GA101 (obinutuzumab) in previously untreated chronic lymphocytic leukemia (CLL) patients. ClinicalTrials.gov Identifier: NCT02315768. Available from: https://clinicaltrials.gov/ct2/show/NCT02315768?term=NCT+023157 68\&rank=1. Accessed August 12, 2016.

41. O'Brien SM, Barrientos JC, Flinn IW, et al. Combination of the Bruton's tyrosine kinase (BTK) inhibitor PCI-32765 with bendamustine (B)/ rituximab $(\mathrm{R})(\mathrm{BR})$ in patients (pts) with relapsed/refractory $(\mathrm{R} / \mathrm{R})$ chronic lymphocytic leukemia (CLL): interim results of a phase $\mathrm{Ib} / \mathrm{II}$ study. J Clin Oncol. 2012;30(suppl 15):6515.

42. ClinicalTrials.gov. First-line therapy with ibrutinib, fludarabine, cyclophosphamide, and obinutuzumab (GA-101) (iFCG) for patients with chronic lymphocytic leukemia (CLL). ClinicalTrials.gov Identifier: NCT02629809. Available from: https://clinicaltrials.gov/ct2/show/ NCT02629809. Accessed August 12, 2016.

43. Woyach JA, Furman RR, Liu TM, et al. Resistance mechanisms for the Bruton's tyrosine kinase inhibitor ibrutinib. N Engl J Med. 2014; 370(24):2286-2294.
OncoTargets and Therapy

\section{Publish your work in this journal}

OncoTargets and Therapy is an international, peer-reviewed, open access journal focusing on the pathological basis of all cancers, potential targets for therapy and treatment protocols employed to improve the management of cancer patients. The journal also focuses on the impact of management programs and new therapeutic agents and protocols on

\section{Dovepress}

patient perspectives such as quality of life, adherence and satisfaction. The manuscript management system is completely online and includes a very quick and fair peer-review system, which is all easy to use. Visit http://www.dovepress.com/testimonials.php to read real quotes from published authors. 